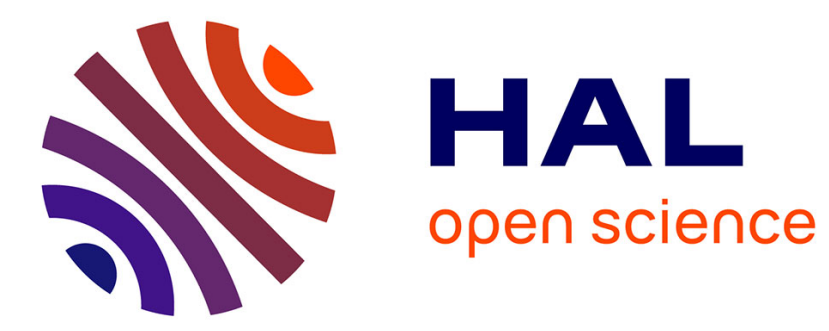

\title{
Busting the efficiency of SAPO-34 catalysts for the methanol-to-olefin conversion by post-synthesis methods
}

Guoju Yang, Ji Han, Yujun Huang, Xiaoxin Chen, Valentin Valtchev

\section{To cite this version:}

Guoju Yang, Ji Han, Yujun Huang, Xiaoxin Chen, Valentin Valtchev. Busting the efficiency of SAPO34 catalysts for the methanol-to-olefin conversion by post-synthesis methods. Chinese Journal of Chemical Engineering, 2020, 28 (8), pp.2022-2027. 10.1016/j.cjche.2020.05.028 . hal-03034305

\section{HAL Id: hal-03034305 \\ https://hal-normandie-univ.archives-ouvertes.fr/hal-03034305}

Submitted on 1 Dec 2020

HAL is a multi-disciplinary open access archive for the deposit and dissemination of scientific research documents, whether they are published or not. The documents may come from teaching and research institutions in France or abroad, or from public or private research centers.
L'archive ouverte pluridisciplinaire HAL, est destinée au dépôt et à la diffusion de documents scientifiques de niveau recherche, publiés ou non, émanant des établissements d'enseignement et de recherche français ou étrangers, des laboratoires publics ou privés. 


\title{
Busting the efficiency of SAPO-34 catalysts for the MTO conversion by post-synthesis methods
}

Guoju YANG ${ }^{1,2, \ddagger}$, Ji HAN ${ }^{1, \ddagger}$, Yujun $\mathrm{HUANG}^{1}$, Xiaoxin $\mathrm{CHEN}^{1, *}$, Valentin VALTCHEV ${ }^{3, *}$

${ }^{1}$ State Key Laboratory of Inorganic Synthesis and Preparative Chemistry, College of Chemistry, Jilin University, Changchun 130012, Jilin, People's Republic of China.

${ }^{2}$ International Center of Future Science, Jilin University, Changchun 130012, Jilin, People's Republic of China.

${ }^{3}$ Normandie Univ, ENSICAEN, UNICAEN, CNRS, Laboratoire Catalyse et Spectrochimie, 6 Marechal Juin, 14050 Caen, France

(C) 2019 The Chemical Industry and Engineering Society of China, and Chemical Industry Press Co. Ltd. All rights reserved.

* Corresponding author. E-mail: chenxiaoxin@jlu.edu.cn, valentin.valtchev@ensicaen.fr

\$ These authors contributed equally.

Article history:

Received DD MM 2020

Revised DD MM 2020

Accepted DD MM 2020

Available online DD MM 2020

\begin{abstract}
As an effective non-petroleum based process for producing light olefins, the methanol-to-olefin (MTO) route has become an indispensable alternative to the industrial production of light olefins. The silicoaluminophosphate SAPO-34 zeolite (CHA-type structure) has proven to be an efficient industrial catalyst for the production of ethylene and propylene by the MTO reaction. However, the inherent structure and related diffusion limitations of SAPO-34 limit the mass transport and thus cause rapid deactivation of the catalyst. Fabrication of hierarchical SAPO-34 zeolite is one of the most effective strategies to address the intrinsic diffusion limitation. As simple, inexpensive, and efficient approach, the post-synthetic route has attracted considerable attention and widely used to introduce secondary meso-/macropores into the microporous SAPO-34 material. Significant effort has been dedicated to the development of post-synthesis strategies to prepare hierarchical
\end{abstract}


SAPO-34 zeolite, thereby enhancing its catalytic performance in the MTO process. This mini-review addresses the post-synthesis preparation of hierarchical SAPO-34 catalysts and their MTO performance. Furthermore, some current problems and prospects of the post-synthesis route to hierarchical SAPO-34 catalysts are also revised. We expect this mini-review to inspire the more efficient preparation of hierarchical SAPO-34 catalysts for the MTO process.

Keywords: Zeolites; SAPO-34; Post-synthesis treatment; Hierarchical; MTO.

\section{Introduction}

Light olefins, such as ethylene, propylene, are essential raw materials in the chemical industry of various polymers.[1,2] Traditionally, light olefins are petrochemical derivatives produced by naphtha cracking. The development of alternative non-oil route for light olefins production is imperative to overcome the expected oil shortage worldwide and meet the increasingly high demand for light olefins. The methanol-to-olefin (MTO) reaction, as a linkage between coal/natural gas industry and chemical production, has provided a successful non-petroleum route to produce light olefins from non-oil resources. Consequently, intense research efforts have been dedicated to the understanding of MTO reaction from both the academia and industry. The MTO reaction was first reported by Mobil Oil Corporation in 1977.[3] Through the years, significant progress was achieved in terms of the reaction mechanism, catalyst's synthesis, and process development in the MTO.[2, 4]

Design and optimization of an efficient catalyst is critical for any industrial process. Microporous crystalline zeolites have been proved to be the most efficient catalysts for the MTO reaction, due to their regular microporous architectures, unique shape selectivity, appropriate acidity, and high thermal and hydrothermal stability. [4-12] Amongst them, the SAPO-34 (CHA-type) silicoaluminophosphate that possesses three-dimensional channels with 8 -ring pore openings $(0.38 \mathrm{~nm} \times 0.38 \mathrm{~nm})$ and moderate acidity is particularly appropriate for the MTO reaction.[13] However, the SAPO-34 catalysts generally suffer from severe transport limitations leading to fast deactivation by the coke deposition.[14, 15$]$ Therefore, various synthetic strategies have been tested to minimize the intrapore diffusion 
limitation in SAPO-34 and improve their MTO performance.[16-18] One of the most widely employed approaches is to introduce secondary meso-/macro-pores into the intrinsic microporous structure of SAPO-34, i.e., the fabrication of a hierarchical porous structure. In this review, we present recent progress in the post-synthesis approaches to hierarchical SAPO-34 zeolites. Besides the post-synthetic methods, the analysis addresses the current challenges and outline the perspectives. The ultimate goal of this mini-review is to highlight the most effective post-synthesis approaches for yielding hierarchical SAPO-34 catalysts with excellent catalytic performance in the MTO reaction.

\section{Synthetic strategies employed in the preparation of hierarchical SAPO-34 zeolite} Materials and Methods

The synthetic routes operated in the development of hierarchical SAPO-34 zeolites can be classified into two groups, i.e., bottom-up and top-down approaches.

The bottom-up approach refers to the use of sacrificial meso-porogens (soft or hard template) besides the organic structure-directing agent (OSDA) in the starting zeolite synthesis system.[19-24] Although it is a flexible and efficient way to prepare hierarchical SAPO-34 there are substantial drawbacks that make this approach not very attractive from a practical viewpoint. First, the high-cost of meso-porogens should be considered in large-scale production. Second, the elimination of the meso-porogen usually includes high-temperature combustion, which is an energy-intensive process. However, the combustion of large organic species leads to the generation of substantial heat and water, which causes the partial collapse of zeolite framework or the generation of extra-framework aluminum species. Furthermore, defective sites might be generated during the formation of hierarchical structures via meso-porogens, which deteriorates catalyst's hydrothermal/mechanical stability. These problems are certainly challenging to be surmounted in large-scale operations.

Compared with the bottom-up method, the alternative top-down route, which includes a post-synthetic chemical etching of zeolite framework, is easier to be implemented and does not require high-temperature treatment. Different chemical etching procedures were 
developed to convert conventional aluminosilicate zeolites in hierarchical materials, such as vapor steaming and various mineral acid and base caustic leaching. [17, 18, 25-32] However, the generation of a hierarchical SAPO-34 material by post-synthesis treatment etching is relatively tricky owing to the alternation of $\mathrm{Al}$ and $\mathrm{P}$ in the framework, the latter being easily destabilized by chemical etching. Therefore, it was highly desirable to develop applicable post-synthetic approaches specific for SAPO-34, which generate hierarchical material without destabilizing the framework and substantially changing the framework composition. Fig. 1 illustrates the impact of the chemical etching on the fabrication of hierarchical SAPO-34 zeolites. In the following section, the representative post-synthesis approaches are summarized and discussed in detail.

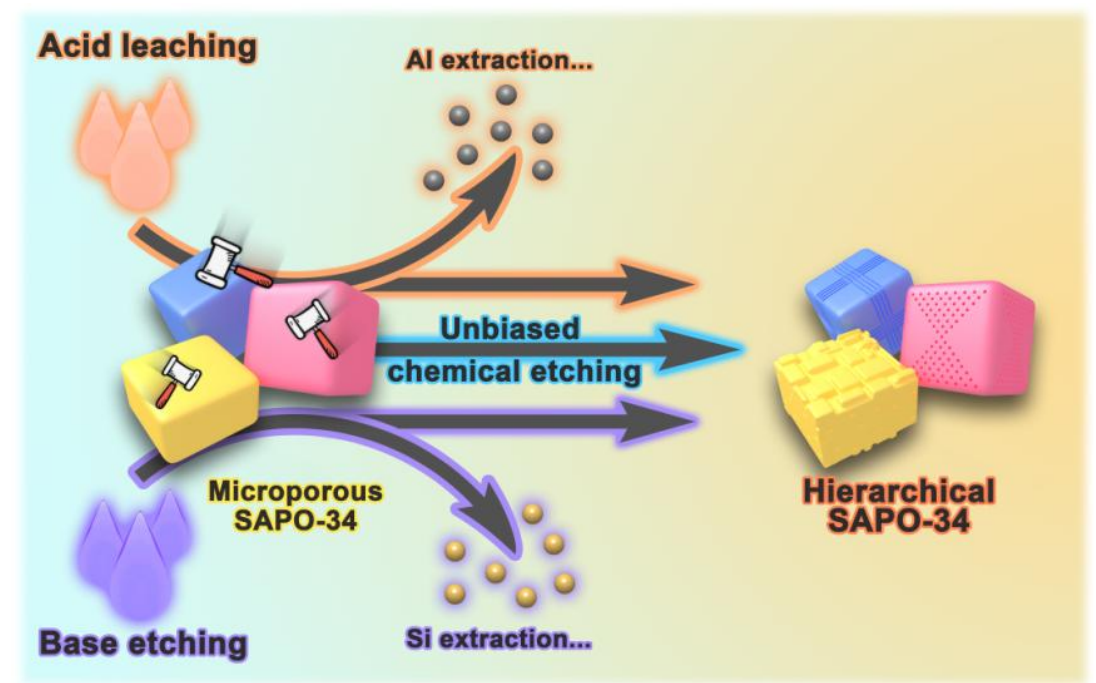

Fig. 1. Conventional acid/base etching and its impact on the composition of hierarchical SAPO-34 zeolite.

\section{Post-synthesis methods applied in the preparation of hierarchical SAPO-34}

The conventional post-synthesis etching is a demetalizing process, which usually involves chemically selective extracting a framework cation, thereby changing the zeolite framework composition and acidity. Since the framework of SAPOs is generally less stable than the aluminosilicate zeolites, it is difficult to tailor SAPO-34 zeolites using traditional acid/base etching. The lower chemical stability of SAPO-34 is due to the fact that the silicon amount is limited, and the aluminum and phosphorous are alternate in the CHA-type framework. Thus, the selective chemical extraction destabilizes the structure 
(Fig. 2). Therefore, only an etching that allows unbiased extraction of framework elements would allow the efficient generation of hierarchical SAPO-34 with retained physicochemical properties.

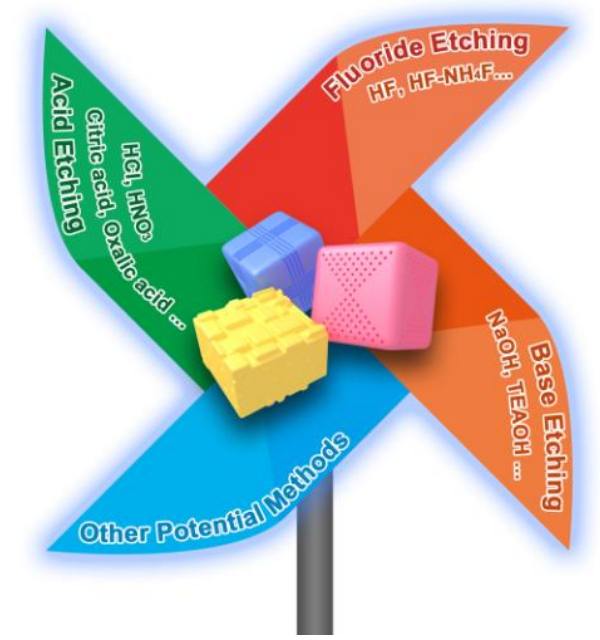

Fig. 2. Summary of the post-synthesis etching approaches used in the preparation of hierarchical SAPO-34.

\subsection{Acid etching}

Various mineral or organic acids have been employed to introduce secondary pores in SAPO-34. Ren et al. reported that SAPO-34 crystals subjected to nitric acid etching exhibit hierarchical structures with butterfly-shaped porous patterns on the faces, as shown in Fig. 3(A).[33] The secondary pores in the obtained hierarchical SAPO-34 comprise meso- and macropores. The oxalic acid was also applied to etch SAPO-34 zeolites. As can be seen in Fig. 3(A), the crystal faces of SAPO-34 after post-etching by oxalic acid exhibit a similar secondary pore system but less obvious butterfly-shaped porous patterns in comparison with those of nitric acid etching SAPO-34. The BET specific surface area of the oxalic acid treated SAPO-34 increased sharply from $665 \mathrm{~m}^{2} / \mathrm{g}$ of parent sample to $876 \mathrm{~m}^{2} / \mathrm{g}$. Compared with the parent counterpart, the obtained hierarchical SAPO-34 shows longer catalyst lifetime and higher selectivity to light olefins in the MTO process.

Qiao et al. prepared hollow SAPO-34 hierarchical crystals with a shell thickness of about $30 \mathrm{~nm}$ by hydrochloric acid etching (Fig. 3(B)).[34] The $\mathrm{HCl}$ acid treatment leads to preferential extraction of $\mathrm{Al}$ and $\mathrm{P}$ resulting in the formation of Si island in the crystal shell. 
Silicon gradient in the parent crystals plays a vital role in the generation of a hollow structure.

A solvent-free process was developed to prepare hierarchical SAPO-34 by using solid oxalic acid. This melting-assisted route is beneficial from a water-saving viewpoint.[35] After post-treatment with solid oxalic acid, there are butterfly patterned abundant meso-/macro-pores penetrating in the SAPO-34 crystals (Fig. 3(C)). The resultant hierarchical SAPO-34 zeolite shows a micro-, meso-, and macro-porous composite pore structure, high BET surface area, as well as a higher concentration of weak acid sites, thus improving the catalytic performance in MTO reactions.
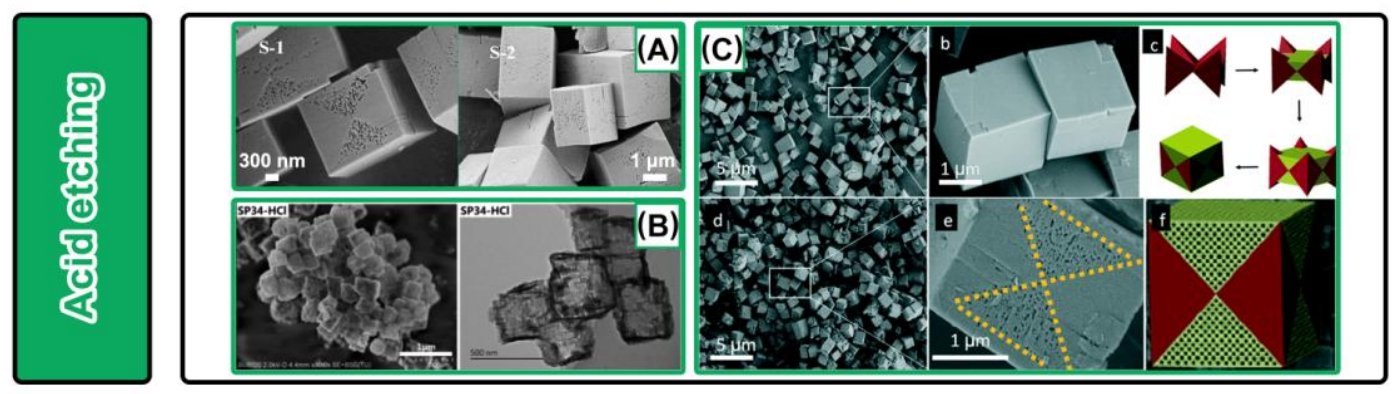

Fig. 3. SAPO-34 zeolites fabricated by acid etching. (A) SEM images of SAPO-34 crystals treated with nitric (S-1) and oxalic (S-2) acid. Reprinted from ref. 29 (Copyright 2017, Elsevier). (B) SEM (left) and TEM (right) images of SAPO-34 leached with $\mathrm{HCl}$. Reprinted from ref. 30 (Copyright 2016, Royal Society of Chemistry). (C) SEM images of SAPO-34 ( $\mathrm{a}$ and $\mathrm{b}$ ) before and ( $\mathrm{d}$ and e) after solid oxalic acid treatment, (c) schematic drawing of the growth of SAPO-34, and (f) schematic illustration of the morphology of treated SAPO-34. Reprinted from ref. 31 (Copyright 2018, Royal Society of Chemistry).

Besides introducing a hierarchical porous structure in SAPO-34 crystals, it is important to tune the content and distribution of silicon, thereby adjusting the acidity of the material. Shen and co-workers prepare the hierarchical SAPO-34 zeolites with slit-shaped mesopores via citric acid etching.[36] Thus generated mesopores start from the crystal surfaces and end at the center of the crystals. The citric acid leaching leads to a substantial increase in the concentrations Lewis and Brønsted acid sites on the external surface of SAPO-34. Still, it decreases the total amount of acid sites. The resultant hierarchical 
SAPO-34 material exhibits enhanced catalytic performance in the MTO reaction with about 2.5 times extended catalytic lifetime and a nearly $8 \%$ improvement of selectivity for ethylene and propylene.

\subsection{Base etching}

The $\mathrm{NaOH}$ aqueous solution is commonly used as an etchant in the preparation of hierarchical aluminosilicate zeolites.[32, 37] However, due to the limited chemical stability, the SAPO structure is very sensitive to $\mathrm{NaOH}$ etching.[38] Liu and co-workers employed the $\mathrm{NaOH}$ aqueous solution to treat SAPO-34 zeolites, which result in the formation of hollow structures which is partially amorphisized.[34]
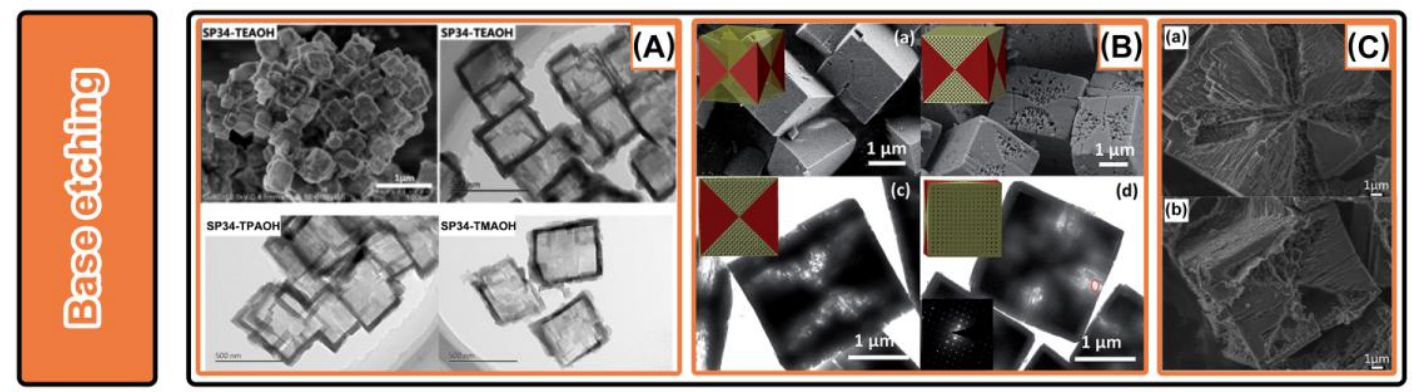

Fig. 4. (A) SEM images of SAPO-34 samples after treatment with TEAOH and TEM images of SAPO-34 samples treated with TPAOH, TEAOH, and TMAOH. Reprinted from ref. 30 (Copyright 2016, Royal Society of Chemistry). (B) SEM images of SAPO-34 crystals (a) before and (b) after TEAOH etching; (c) TEM images of (c) a side face with touching triangles and (d) a side face without triangle dissolution. Insets: Schematics illustration of (a) parent SAPO-34 and (b) hierarchical SAPO-34 crystals, (c) and (d) illustration of the dissolution observed by TEM, and (d, left, down) selected area electron diffraction (SAED) patterns. Reprinted from ref. 36 (Copyright 2016, Royal Society of Chemistry). (C) SEM images of the hierarchical SAPO-34 samples etched at (a) $180{ }^{\circ} \mathrm{C}$ for $24 \mathrm{~h}$ and (b) $180{ }^{\circ} \mathrm{C}$ for $36 \mathrm{~h}$. Reprinted from ref. 37 (Copyright 2019, Royal Society of Chemistry).

Compared with the strongly alkaline inorganic base, the organic base with moderate strength, are expected to be more appropriate in terms of gentle treatment and thus to preserve the crystallinity of SAPO-34.[38] Liu and co-workers prepared hollow SAPO-34 
crystals with a shell thickness of $50 \mathrm{~nm}$ through post-etching with tetraethylammonium hydroxide $(\mathrm{TEAOH})$, tetrapropylammonium hydroxide $(\mathrm{TPAOH})$, tetramethylammonium hydroxide (TMAOH) and diethylamine (DEA), as shown in Fig. 4(A). They use relatively high etching temperature $\left(180{ }^{\circ} \mathrm{C}\right)$. According to these authors, the abundant and interconnected Si-O-Al domains that are highly stable in the SAPO framework are of great help to endure the base leaching. Owing to the higher Si content in the rim of the crystals hollow structures were formed.[38] These very open SAPO-34 materials demonstrated the enhanced catalytic performance in the MTO reaction.

Zeng et al. performed the post-treatment of SAPO-34 zeolites in a lower concentrated TEAOH etching solution and using lower etching temperature $\left(90{ }^{\circ} \mathrm{C}\right)$.[39] Different from the hollow structures reported by Liu et al.,[34] the obtained hierarchical SAPO-34 zeolites exhibit symmetric meso-/macropores dissolution with triangle pore patterns (Fig. 4(B)). The different etching patterns might be a consequence of different templates used by the two groups (triethylamine by Zeng et al., and TEAOH and TMEDA by Liu et al.), which might cause the different distribution of the framework atoms. No matter of different etching patterns, the catalytic lifetime of the obtained hierarchical zeolites was significantly prolonged, and the selectivity of light olefins enhanced.

In order to develop an efficient post-synthetic treatment method to hierarchical SAPO-34 with minimum mass loss, trimethylamine (TEA) aqueous solution was used as an etchant.[40] The particularity of this treatment is that the etching is coupled with a recrystallization process, as dissolution and recrystallization occur simultaneously. Thus a high yield of hierarchical SAPO-34 zeolites (ca. 85\%) with larger secondary pores after post-etching in TEA solution was obtained. The type and the level of dissolution are dependent on the treatment conditions (temperature, time, etc.), as shown in Fig. 4(C). Such an approach ensures less mass loss while retains the chemical composition. Meanwhile, there is an increase in the external surface area and the mesopore volume during the introduction of secondary porosity via such post-etching in TEA solution. Consequently, the resultant hierarchical SAPO-34 catalysts show improved catalytic activity in the MTO reaction due to the remarkably enhanced transport properties coupled with modified acidity. 


\subsection{Fluoride etching post-synthesis}

Hydrofluoric acid (HF) is commonly used to dissolve silicon-containing materials. Valtchev and co-workers have developed fluorine-based methods for the preparation of hierarchical zeolite materials by post-synthesis etching.[30, 41] The particularity of the method is the unbiased dissolution of framework $\mathrm{Si}$ and $\mathrm{Al}$, thus retaining the chemical composition of the material. This is possible by employing the bi-fluoride anion as an etching agent, achieved by mixing $\mathrm{HF}$ and $\mathrm{NH}_{4} \mathrm{~F}$.[42] Later, the same group reported the unbiased chemical etching based on the sole use of $\mathrm{NH}_{4} \mathrm{~F} .[43,44]$ The fluoride post-etching method is very flexible and controllable for regulating both the density and size of the secondary pore system.[45-49]

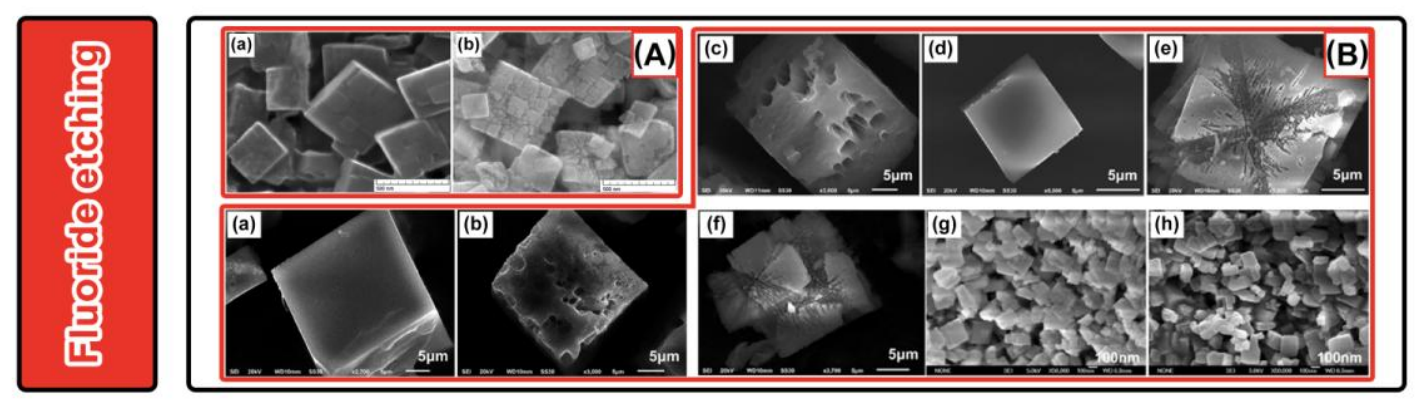

Fig. 5. (A) Representative low magnification SEM micrographs of the parent SAPO-34 and the hierarchical material obtained by $30 \mathrm{~min}$ ultrasonic treatment in fluoride medium. Reprinted from ref. 47 (Copyright 2016, Royal Society of Chemistry). (B) SEM images of the parent and fluoride medium post-treated samples: SAPO-34-Mor: (a) parent SAPO-34, and treated for (b) 30 and (c) 60 min; SAPO-34-TEA: (d) parent SAPO-34, and treated for (e) 30 and (f) $60 \mathrm{~min}$; SAPO-34-TEAOH: (g) parent SAPO-34, and (h) treated for $15 \mathrm{~min}$. Reprinted from ref. 48 (Copyright 2016, Elsevier).

The unbiased chemical etching of zeolite framework is particularly appropriate for the etching SAPO-type materials. In 2016, Chen et al. applied the fluoride post-synthesis route to fabricate hierarchical SAPO-34 zeolites.[50] By controlling the ratio between HF and $\mathrm{NH}_{4} \mathrm{~F}$ in the etching solution and using ultrasonic radiation, hierarchical SAPO-34 was prepared. Noteworthy, the preferential dissolution of highly defected interfaces between crystalline domains was observed, thus only the most crystalline part of SAPO-34 remain after the etching (Fig. 5(A)). The number of Brønsted acid sites of the hierarchical materials 
decreases substantially during the fluoride treatment. Compared to the parent sample, the obtained hierarchical SAPO-34 exhibits longer catalytic lifetime and higher selectivity of low carbon olefins in the MTO reaction. The improved catalytic performance is attributed to the remarkably enhanced mass transportation in CHA structure and preserved highly crystalline domains, as well as the more appropriate moderate acid strengths (Table S1). Chen et al. have also investigated the effect of fluoride etching on SAPO-34 crystals templated by morpholine, triethylamine, and tetraethylammonium.[51] The impact of the OSDA on the formation of a hierarchical SAPO-34 was studied in detail. The authors reported that the dissolution process strongly depended on the organic templates employed in the synthesis of SAPO-34 (Fig. 5(B)). The hierarchical SAPO-34 catalysts exhibited higher selectivity to $\mathrm{C}_{3} \mathrm{H}_{6}$ than the parent SAPO-34 in the MTO reaction. It was also found that the post-synthesis fluoride etching not only generates a secondary large pore system in SAPO-34, but also extracts the silicon preferentially at highly defected zones between the crystalline domains. Thus, both the large pore generation and the decrease of Si content are beneficial for improving the catalytic performance of SAPO-34.

Alternative etching agents that could provide hierarchical SAPO-34 material are reported (Table 1). In general, a hierarchical SAPO-34 can be obtained with any enchantable to dissolve the CHA-framework. 
Table 1. Summary of various leaching agents employed for the post-treatment of SAPO-34 zeolites.

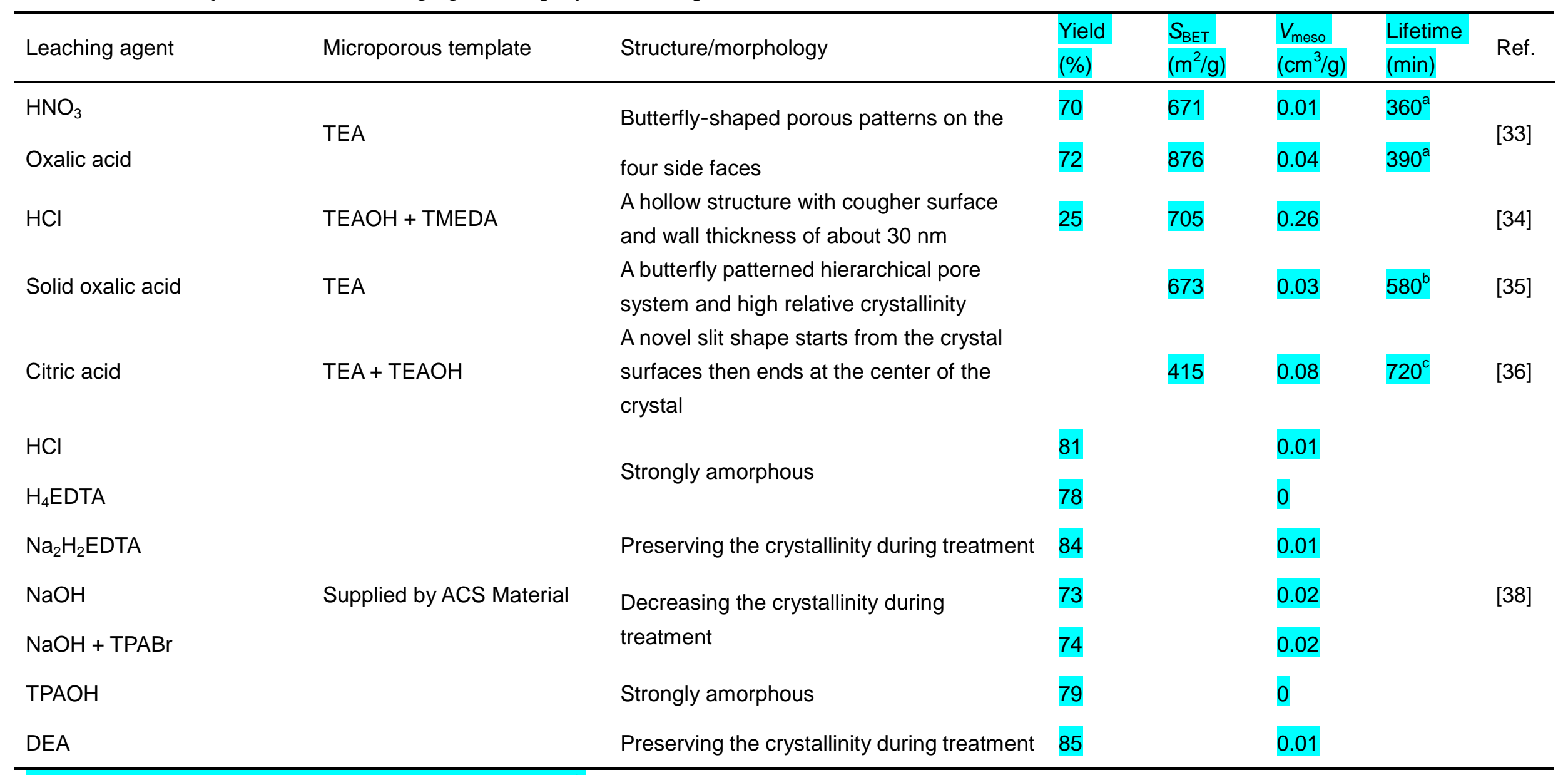

${ }^{a}$ Catalyst weight $=3 \mathrm{~g}(20-40 \mathrm{mesh}), \mathrm{T}=723 \mathrm{~K}, \mathrm{WHSV}=1 \mathrm{~h}^{-1}$.

${ }^{\mathrm{b}}$ Catalyst weight $=3 \mathrm{~g}$ (20-40 mesh), T $=673 \mathrm{~K}, \mathrm{WHSV}=1 \mathrm{~h}^{-1}$.

${ }^{\mathrm{C}}$ Catalyst weight $=1 \mathrm{~g}(40-60 \mathrm{mesh}), \mathrm{T}=673 \mathrm{~K}, \mathrm{WHSV}=1 \mathrm{~h}^{-1}$.

Table 1. Continued 


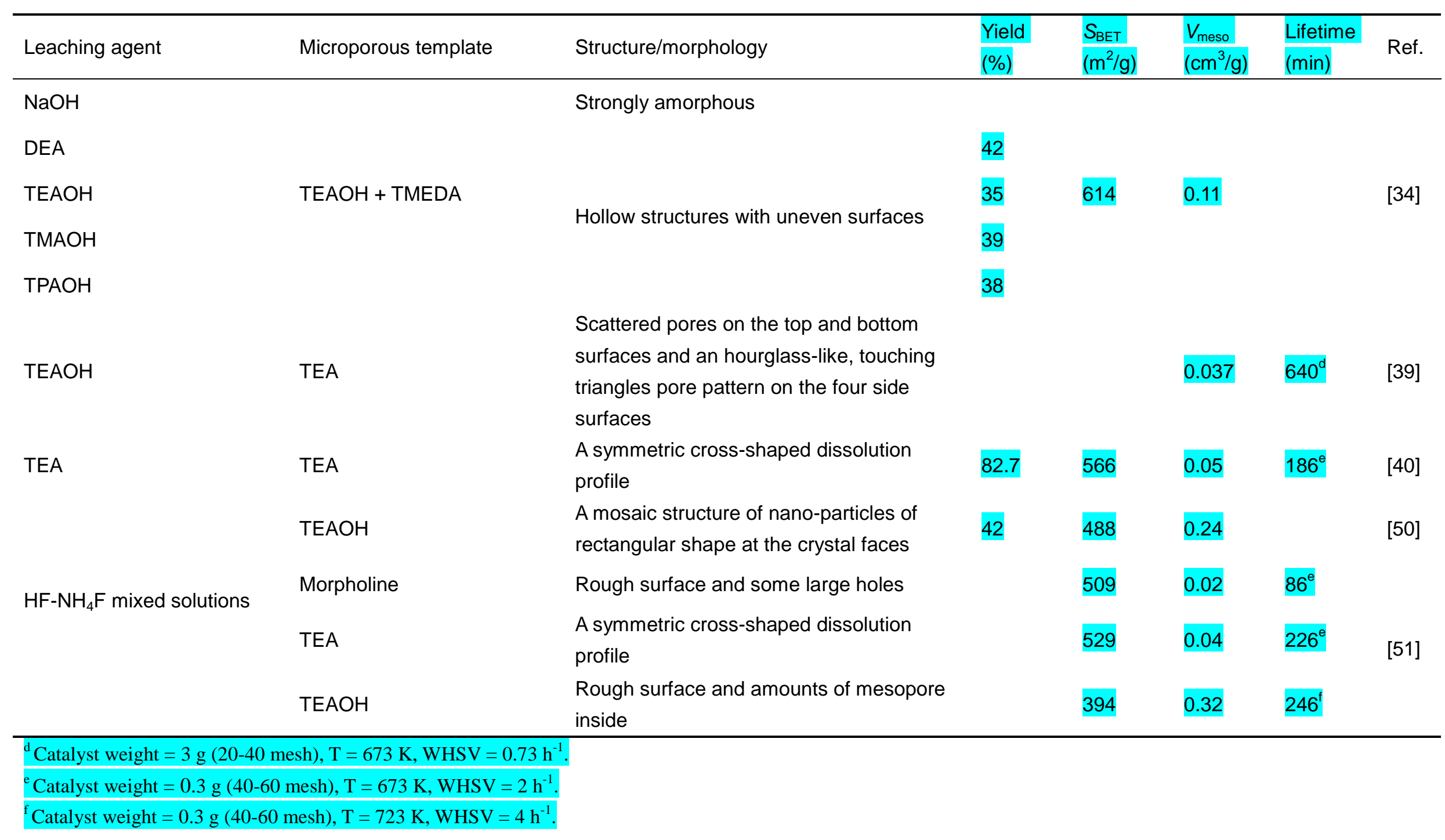




\section{Conclusion and outlook}

The practical importance of the MTO process continuously boosts the development and optimization of SAPO-34-based catalysts. The fabrication of hierarchical structures in the microporous SAPO-34 zeolite by the facile post-synthesis method can improve mass-transfer resistance, open the access to the active-sites, modify the acidity and retard coke deposition. Therefore, it has been one of the most promising routes to prepare hierarchical SAPO-34 zeolite to facilitate its catalytic performance in MTO reactions.

However, the post-synthesis method modifications are often at the expense of the framework stability, crystallinity, and acidity. Moreover, it is important to gain precise regulation of hierarchical characteristics and active sites distribution for the construction of an efficient SAPO-34 catalysts. The efficient chemical etching coupled with the in-situ recrystallization process is expected to address stability and crystallinity issues.

The post-synthesis chemical etching also leads to substantial losses of crystalline material that could go over $50 \mathrm{wt} . \%$. Furthermore, the use of an etching agent raises the synthetic cost, and in general, it is not environmentally benign. Therefore, it is highly desirable to optimize the current post-synthesis methods further. The development of alternative, economic, green, and efficient post-synthesis strategies to meet the increasing demand for hierarchical SAPO-34 is also highly desired. Hence, the solvent-free method presents considerable interest and an attractive alternative for the fabrication of hierarchical SAPO-34 catalysts.

This mini-review summarizes the most important issues related to the preparation of hierarchical SAPO-34 catalysts by post-synthetic treatment. Addressing these issues will open the boulevard to a more rational design of highly performing materials, and guide the future direction in this field.

\section{Acknowledgements}

This work is supported by the National Natural Science Foundation of China (Grant 21971082) and the Jilin Province Science and Technology Development Plan (Grant 20190201229JC and 20200201096JC). G.Y thanks the China Postdoctoral Science 
Foundation (2018M640280 and 2019T120235) for supporting this work. And this work acknowledges the National 111 Project (B17020). X.C. and V.V. acknowledge the collaboration in the framework of joint Sino-French international laboratory "Zeolites".

\section{References:}

[1] M. Stocker, Methanol-to-hydrocarbons: Catalytic materials and their behavior, Microporous Mesoporous Mater. 29 (1-2) (1999) 3-48.

[2] M. Yang, D. Fan, Y. Wei, P. Tian, Z. Liu, Recent progress in methanol-to-olefins (MTO) catalysts, Adv. Mater. 31 (50) (2019) 1902181.

[3] C.D. Chang, A.J. Silvestri, The conversion of methanol and other O-compounds to hydrocarbons over zeolite catalysts, J. Catal. 47 (2) (1977) 249-259.

[4] P. Tian, Y.X. Wei, M. Ye, Z.M. Liu, Methanol to olefins (MTO): From fundamentals to commercialization, ACS Catal. 5 (3) (2015) 1922-1938.

[5] J. Yu, R. Xu, Rational approaches toward the design and synthesis of zeolitic inorganic open-framework materials, Acc. Chem. Res. 43 (9) (2010) 1195-1204.

[6] Z. Wang, J. Yu, R. Xu, Needs and trends in rational synthesis of zeolitic materials, Chem. Soc. Rev. 41 (5) (2012) 1729-1741.

[7] Y. Li, J. Yu, New stories of zeolite structures: Their descriptions, determinations, predictions, and evaluations, Chem. Rev. 114 (14) (2014) 7268-7316.

[8] B.M. Weckhuysen, J. Yu, Recent advances in zeolite chemistry and catalysis, Chem. Soc. Rev. 44 (20) (2015) 7022-7024.

[9] Y. Li, L. Li, J.H. Yu, Applications of zeolites in sustainable chemistry, Chem 3 (6) (2017) 928-949.

[10] Q. Sun, Z. Xie, J. Yu, The state-of-the-art synthetic strategies for SAPO-34 zeolite catalysts in methanol-to-olefin conversion, Natl. Sci. Rev. 5 (4) (2018) 542-558.

[11] G. Yang, S.A. Akhade, X. Chen, Y. Liu, M.-S. Lee, V.-A. Glezakou, R. Rousseau, J.A. Lercher, The Nature of Hydrogen Adsorption on Platinum in the Aqueous Phase, Angew. Chem., Int. Ed. 58 (11) (2019) 3527-3532.

[12] G. Yang, J. Han, Z. Qiu, X. Chen, Z. Feng, J. Yu, An amino acid-assisted approach to fabricate nanosized hierarchical TS-1 zeolites for efficient oxidative desulfurization, Inorg. 
Chem. Front. 7 (10) (2020) 1975-1980.

[13] B.M. Lok, C.A. Messina, R.L. Patton, R.T. Gajek, T.R. Cannan, E.M. Flanigen, Silicoaluminophosphate molecular sieves: another new class of microporous crystalline inorganic solids, J. Am. Chem. Soc. 106 (20) (1984) 6092-6093.

[14] D. Chen, K. Moljord, A. Holmen, A methanol to olefins review: Diffusion, coke formation and deactivation SAPO type catalysts, Microporous Mesoporous Mater. 164 (2012) 239-250.

[15] S. Gao, S. Xu, Y. Wei, Q. Qiao, Z. Xu, X. Wu, M. Zhang, Y. He, S. Xu, Z. Liu, Insight into the deactivation mode of methanol-to-olefins conversion over SAPO-34: Coke, diffusion, and acidic site accessibility, J. Catal. 367 (2018) 306-314.

[16] R. Bai, Y. Song, Y. Li, J. Yu, Creating hierarchical pores in zeolite catalysts, Trends Chem. 1 (6) (2019) 601-611.

[17] J. Pérez-Ramírez, C.H. Christensen, K. Egeblad, C.H. Christensen, J.C. Groen, Hierarchical zeolites: enhanced utilisation of microporous crystals in catalysis by advances in materials design, Chem. Soc. Rev. 37 (11) (2008) 2530-2542.

[18] V. Valtchev, G. Majano, S. Mintova, J. Pérez-Ramírez, Tailored crystalline microporous materials by post-synthesis modification, Chem. Soc. Rev. 42 (1) (2013) 263-290.

[19] F. Schmidt, S. Paasch, E. Brunner, S. Kaskel, Carbon templated SAPO-34 with improved adsorption kinetics and catalytic performance in the MTO-reaction, Microporous Mesoporous Mater. 164 (2012) 214-221.

[20] A.Z. Varzaneh, J. Towfighi, S. Sahebdelfar, Carbon nanotube templated synthesis of metal containing hierarchical SAPO-34 catalysts: Impact of the preparation method and metal avidities in the MTO reaction, Microporous Mesoporous Mater. 236 (2016) 1-12.

[21] Y. Liu, L. Wang, J. Zhang, F. Chen, M. Anpo, Preparation of macroporous SAPO-34 microspheres by a spray drying method using polystyrene spheres as hard template, Res. Chem. Intermed. 37 (8) (2011) 949-959.

[22] Q. Sun, N. Wang, D. Xi, M. Yang, J. Yu, Organosilane surfactant-directed synthesis of hierarchical porous SAPO-34 catalysts with excellent MTO performance, Chem. Commun. 50 (49) (2014) 6502-6505. 
[23] F. Wang, L. Sun, C. Chen, Z. Chen, Z. Zhang, G. Wei, X. Jiang, Polyethyleneimine templated synthesis of hierarchical SAPO-34 zeolites with uniform mesopores, RSC Adv. 4 (86) (2014) 46093-46096.

[24] K. Egeblad, C.H. Christensen, M. Kustova, C.H. Christensen, Templating mesoporous zeolites, Chem. Mater. 20 (3) (2008) 946-960.

[25] Y. Jiao, L. Forster, S. Xu, H. Chen, J. Han, X. Liu, Y. Zhou, J. Liu, J. Zhang, J. Yu, C. D'Agostino, X. Fan, Creation of Al-enriched mesoporous ZSM-5 nanoboxes with high catalytic activity: Converting tetrahedral extra-framework Al into framework sites by post treatment, Angew. Chem., Int. Ed. (2020) 10.1002/ange.202002416.

[26] Y. Jiao, A.-L. Adedigba, Q. He, P. Miedziak, G. Brett, N.F. Dummer, M. Perdjon, J. Liu, G.J. Hutchings, Inter-connected and open pore hierarchical TS-1 with controlled framework titanium for catalytic cyclohexene epoxidation, Catal. Sci. Technol. 8 (8) (2018) 2211-2217. [27] R. Zhang, P. Zhong, H. Arandiyan, Y. Guan, J. Liu, N. Wang, Y. Jiao, X. Fan, Using ultrasound to improve the sequential post-synthesis modification method for making mesoporous Y zeolites, Front. Chem. Sci. Eng. 14 (2) (2020) 275-287.

[28] S. van Donk, A.H. Janssen, J.H. Bitter, K.P. de Jong, Generation, characterization, and impact of mesopores in zeolite catalysts, Catal. Rev. 45 (2) (2003) 297-319.

[29] V. Valtchev, S. Mintova, Hierarchical zeolites, MRS Bull. 41 (9) (2016) 689-693.

[30] Z. Qin, J.-P. Gilson, V. Valtchev, Mesoporous zeolites by fluoride etching, Curr. Opin. Chem. Eng. 8 (2015) 1-6.

[31] F. Thibault-Starzyk, I. Stan, S. Abelló, A. Bonilla, K. Thomas, C. Fernandez, J.-P. Gilson, J. Pérez-Ramírez, Quantification of enhanced acid site accessibility in hierarchical zeolites - The accessibility index, J. Catal. 264 (1) (2009) 11-14.

[32] D. Verboekend, J. Pérez-Ramírez, Design of hierarchical zeolite catalysts by desilication, Catal. Sci. Technol. 1 (6) (2011) 879-890.

[33] S. Ren, G. Liu, X. Wu, X. Chen, M. Wu, G. Zeng, Z. Liu, Y. Sun, Enhanced MTO performance over acid treated hierarchical SAPO-34, Chin. J. Catal. 38 (1) (2017) 123-130. [34] Y. Qiao, M. Yang, B. Gao, L. Wang, P. Tian, S. Xu, Z. Liu, Creation of hollow SAPO-34 single crystals via alkaline or acid etching, Chem. Commun. 52 (33) (2016) 5718-5721. 
[35] Z. Liu, S. Ren, X. Yu, X. Chen, G. Wang, X. Wu, G. Yu, M. Qiu, C. Yang, Y. Sun, Melting-assisted solvent-free synthesis of hierarchical SAPO-34 with enhanced methanol to olefins (MTO) performance, Catal. Sci. Technol. 8 (2) (2018) 423-427.

[36] W. Jin, B. Wang, P. Tuo, C. Li, L. Li, H. Zhao, X. Gao, B. Shen, Selective desilication, mesopores formation, and MTO reaction enhancement via citric acid treatment of zeolite SAPO-34, Ind. Eng. Chem. Res. 57 (12) (2018) 4231-4236.

[37] S. Abello, A. Bonilla, J. Perez-Ramirez, Mesoporous ZSM-5 zeolite catalysts prepared by desilication with organic hydroxides and comparison with $\mathrm{NaOH}$ leaching, Appl. Catal., A 364 (1-2) (2009) 191-198.

[38] D. Verboekend, M. Milina, J. Pérez-Ramírez, Hierarchical silicoaluminophosphates by postsynthetic modification: Influence of topology, composition, and silicon distribution, Chem. Mater. 26 (15) (2014) 4552-4562.

[39] X. Liu, S. Ren, G. Zeng, G. Liu, P. Wu, G. Wang, X. Chen, Z. Liu, Y. Sun, Coke suppression in MTO over hierarchical SAPO-34 zeolites, RSC Adv. 6 (34) (2016) 28787-28791.

[40] Y. Pan, G. Chen, G. Yang, X. Chen, J. Yu, Efficient post-synthesis of hierarchical SAPO-34 zeolites via organic amine etching under hydrothermal conditions and their enhanced MTO performance, Inorg. Chem. Front. 6 (5) (2019) 1299-1303.

[41] V. Valtchev, E. Balanzat, V. Mavrodinova, I. Diaz, J. El Fallah, J.-M. Goupil, High energy ion irradiation-induced ordered macropores in zeolite crystals, J. Am. Chem. Soc. 133 (46) (2011) 18950-18956.

[42] Z. Qin, L. Lakiss, J.-P. Gilson, K. Thomas, J. Goupil, C. Fernandez, V. Valtchev, Chemical equilibrium controlled etching of MFI-type zeolite and its influence on zeolite structure, acidity, and catalytic activity, Chem. Mater. 25 (14) (2013) 2759-2766.

[43] Z. Qin, G. Melinte, J.-P. Gilson, M. Jaber, K. Bozhilov, P. Boullay, S. Mintova, O. Ersen, V. Valtchev, The mosaic structure of zeolite crystals, Angew. Chem., Int. Ed. 128 (48) (2016) 15273-15276.

[44] Z. Qin, K.A. Cychosz, G. Melinte, H. El Siblani, J.-P. Gilson, M. Thommes, C. Fernandez, S. Mintova, O. Ersen, V. Valtchev, Opening the cages of Faujasite-type zeolite, J. Am. Chem. Soc. 139 (48) (2017) 17273-17276. 
[45] J. Přech, K.N. Bozhilov, J. El Fallah, N. Barrier, V. Valtchev, Fluoride etching opens the structure and strengthens the active sites of the layered ZSM-5 zeolite, Microporous Mesoporous Mater. 280 (2019) 297-305.

[46] Z. Qin, L. Hafiz, Y. Shen, S.V. Daele, P. Boullay, V. Ruaux, S. Mintova, J.-P. Gilson, V. Valtchev, Defect-engineered zeolite porosity and accessibility, J. Mater. Chem. A 8 (7) (2020) 3621-3631.

[47] Z. Qin, L. Pinard, M.A. Benghalem, T.J. Daou, G. Melinte, O. Ersen, S. Asahina, J.-P. Gilson, V. Valtchev, Preparation of single-crystal "house-of-cards"-like ZSM-5 and their performance in ethanol-to-hydrocarbon conversion, Chem. Mater. 31 (13) (2019) 4639-4648.

[48] V. Babić, L. Tang, Z. Qin, L. Hafiz, J.-P. Gilson, Comparative study of zeolite L etching with ammonium fluoride and ammonium bifluoride solutions, Adv. Mater. Interfaces (2020) DOI:10.1002/admi.20200034.

[49] K.-G. Haw, S. Moldovan, L. Tang, Z. Qin, Q. Fang, S. Qiu, V. Valtchev, A sponge-like small pore zeolite with great accessibility to the micropores, Inorg. Chem. Front. (2020) DOI:10.1039/D1030QI00261E.

[50] X. Chen, A. Vicente, Z. Qin, V. Ruaux, J.-P. Gilson, V. Valtchev, The preparation of hierarchical SAPO-34 crystals via post-synthesis fluoride etching, Chem. Commun. 52 (17) (2016) 3512-3515.

[51] X. Chen, D. Xi, Q. Sun, N. Wang, Z. Dai, D. Fan, V. Valtchev, J. Yu, A top-down approach to hierarchical SAPO-34 zeolites with improved selectivity of olefin, Microporous Mesoporous Mater. 234 (2016) 401-408. 